DOI: 10.17805/zpu.2015.3.3

\title{
Электронные формы учебников в образовательном пространстве
}

\author{
B. А. СИтАРОВ \\ (МОСКОВСКИЙ ГУМАНИТАРНЫЙ УНИВЕРСИТЕТ)
}

12 июня 2015 г. издательство «Дрофа» (г. Москва) на своем сайте провело вебинар «Электронные формы учебников в образовательном пространстве. Учись учиться по-новому. Электронные учебники издательства "Дрофа" - шаг к получению высшего образования». Специально для основного доклада был приглашен известный российский ученый - доктор педагогических наук, профессор, заведующий кафедрой педагогики и психологии высшей школы Московского гуманитарного университета В. А. Ситаров.

В своем выступлении В. А. Ситаров отмечает то важное, что позволяют решать электронная форма обучения в дополнение к традиционным формам. По его словам, считалось, что знания и информация не находятся в тесной взаимосвязи между собой, а порой и противоречат друг другу. Потому что в школьных учебниках излагались и излагаются «знания», содержание учебников отвечает определенным требованиям, критериям, которые выстроены в своей иерархии. Информация этими критериями не обладает, поэтому ее и нет в школьных учебниках. Но сама по себе информация очень привлекательна. Сегодня и школьники, и взрослые ее получают из разных источников. Появление электронных учебников в школе благоприятствует тому, что имеющаяся в них дополнительная информация, которая сопровождает основной материал, будет расширять основное содержание учебника, формировать у учащихся познавательный интерес. И противоречие между знанием и информацией будет сниматься.

Докладчик дает характеристики электронным учебникам. Заслуга электронного учебника состоит прежде всего в том, что в нем реализуется принцип наглядности в обучении, он позволяет в какой-то степени снять противоречие, существующее в системе «ученик содержание - методы»; дает возможность решать задачи мотивации обучения, воспитательные задачи, формирование представлений о взаимопереплетении дисциплин и пр. Однако автор также указывает на необходимость и важность личного взаимодействия между преподавателем и учеником, личного примера учителя.

Представляем вниманию наших читателей полную стенограмму выступления докладчика.

Ключевые слова: вебинар, электронные учебники, информационная образовательная среда, электронное обучение, электронные средства обучения.

\section{ВВЕАЕНИЕ}

обрый день, уважаемые коллеги! Сегодня мы поговорим об электронных учебниках, которые должны войти в нашу образовательную школьную жизнь начиная с 1 сентября 2015 г. Хочется нам или нет, нравится это или нет, но это будет, так как на это существует приказ Министерства образования и науки РФ. Это, так сказать, одна сторона медали.

Но есть и другая. Аопустим, приказа об обязательном использовании электронных учебников в школе нет. Но есть реальная жизнь, в которой уже с дошкольного возраста практически каждый ребенок держит в руках то или иное электронное средство, которое он использует в своей жизни - играет, общается, развлекается, получает информацию.

И обращаясь к такой теме, я ознакомился с электронными учебниками издательства «Арофа». И как мне представляется, пользуясь электронными учебниками в школе, вузы получат достойных первокурсников и в будущем хороших специалистов в нашей стране. 


\section{ЗНАНИЕ И ИНФОРМАЦИЯ}

В последние десятилетия в нашу жизнь вошли такие широко употребляемые слова, термины, за которыми бывает очень трудно раскрыть их содержание: «информация», «информационная образовательная среда», «электронное обучение», «электронный курс», «электронные средства обучения», «компьютерная среда», «мультимедийные средства», «информационное общество»и еще множество других. Если говорить с научной точки зрения, то за каждым термином скрывается понятие, а каждое понятие имеет свое определение, а каждое определение понятия содержит определенные существенные признаки, без которых данное понятие не существует. Педагогическая наука оперирует в основном терминами, понятиями, словами, понятными практически каждому человеку независимо от его образования. Каждый считает себя специалистом, каждый знает - как нужно учить, как нужно воспитывать, как нужно образовывать и т. А. В результате складывается кажущееся представление о том, что если мы все говорим на одном понятном всем языке, то, соответственно, и каждому человеку понятно - о чем идет речь. Но это далеко не так.

К сожалению, большинство людей, не задумываясь, оперируют этими понятиями. Это приводит к их размытости, ложной синонимичности.

Когда мы говорим об электронном учебнике (есть синоним - «электронный учебный курс»), то, естественно, подразумеваем, что существует электронная образовательная среда школы. Но аналогично существует также и электронная образовательная среда в вузе, которая аккумулирует интеллектуальный потенциал всех субъектов вуза, и в первую очередь как самих обучаемых, так и преподавателей, а также различные программно-методические и технические ресурсы.

Прежде чем перейти к анализу электронных учебников, я в своем выступлении буду затрагивать и личность школьника, потому что сегодняшний школьник - это завтрашний студент.

Наряду с термином «знание» существует и термин «информация». Традиционно считалось еще до появления различных электронных средств обучения, что знания и информация не находятся в тесной взаимосвязи между собой, а порой и противоречат друг другу. Почему? Потому что в школьных учебниках излагались и излагаются «знания». И каждый школьный учебник представляет собой своеобразный «слепок», отражение той отрасли научного знания, той науки, которую он представляет в школьном предмете. Не так просто попасть тому или иному материалу в школьный учебник. Содержание школьных учебников отвечает определенным требованиям, критериям, которые выстроены в своей иерархии: в них должны быть научные факты, сформулированы научные понятия (определения), должны быть законы, теории (Ситаров, 2014).

Информация этими критериями не обладает, поэтому ее и нет в школьных учебниках. Но все дело в том, что сама по себе информация очень интересна, привлекательна. Школьники и взрослые ее получают из Интернета, газет, журналов, бесед, общения и т. А. Но пока информация проходит стадии ее трансформации в знание, проходит немало времени - и она устаревает и уже не представляет интереса для школьника.

Очень хочется надеяться на то, что появление электронных учебников в школе будет благоприятствовать тому, что имеющаяся в них дополнительная информация, которая сопровождает основной материал, будет расширять основное содержание учебника, увлекательно уводить школьника в необъятные просторы научного знания 
и тем самым формировать у учащихся познавательный интерес. Противоречие между «знанием» и «информацией» будет постепенно сниматься и уже не будет стоять так остро.

Первокурсники, которые приходят к нам в вузы, как правило, держат электронные средства в своей руке в течение всего учебного дня. И мы должны воспользоваться этой ситуаций и ответить на вопрос: «А как электронные средства можно әффективно использовать в учебном процессе?» И вот здесь мы надеемся на методический потенциал учительского сообщества, который, обладая методическими знаниями, своими авторскими методиками изложения материала, «приучит» в той или иной степени получать дополнительные знания, используя электронные средства. Школа будет благоприятствовать работе с электронными учебниками и, таким образом, подготовит грамотных пользователей электронных ресурсов, что крайне важно и при их дальнейшем обучении в вузе.

Конечно, ошибочно думать, что электронный учебник будет панацеей от всех бед, существующих в образовании. Но некоторые существующие проблемы он все-таки решит. Так, материалы, которые имеются в электронных учебниках и с которыми я ознакомился, в той или иной степени заставят учеников думать. Что я имею в виду? По моим наблюдениям, тот или иной вопрос, заданный студентам, побуждает их мгновенно находить ответ в Интернете, пользуясь подручными электронными средствами. Но если возникает вопрос дискуссионного характера? Например, на семинаре по курсу «Теория обучения» студентам предложено обосновать свое мнение на высказывание Э. Стоунса «Разные читатели видят в книге одни и те же слова, но воспринимают их по-разному». Многие студенты затруднялись с ответом и, обосновывая свою точку зрения, отмечали, что им трудно думать.

Поэтому одна из задач, существующих как в школе, так и в вузе, - способствовать тому, чтобы учащиеся научились думать. Особенно в вузе, где им предоставлено столько свободы по сравнению со школой, что многие не могут с ней справиться (нет классного журнала, дневника, нет строгой проверки посещаемости, не вызывают родителей и т. А.).

Основываясь на развитии образования в нашей стране, я буду говорить о поддержке электронных учебников, пытаясь тем или иным способом аргументировать свои положения.

Сам я глубоко убежден в том, что личность учителя не может заменить никакой учебник. Учителя, которые начинали свою деятельность еще в Советском Союзе, хорошо помнят о том, какой авторитет был у учителя, особенно у учителя начальной школы, в семье ученика, среди его сверстников, друзей. Мы все знаем вот эту фразу: «А учительница сказала...» То, что сказала учительница, было мощным, определяющим аргументом для ученика как в плане знания, так и в плане поведения. И мы всегда должны об этом помнить. Между прочим, еще английский психолог Роберт Бернс в своей книге «Развитие Я-концепции и воспитание» описал феномен советского учителя начальных классов - уникального и неповторимого. Это было заметно уже с приемной комиссии, когда абитуриенты подавали документы для поступления на факультет начальных классов. Несмотря на высокий конкурс, который традиционно существовал на подобные факультеты, абитуриентов невозможно было уговорить перевести документы для поступления на другую педагогическую специальность, где у них шансов для зачисления в институт было намного больше. 
ХАРАКТЕРИСТИКИ ЭАЕКТРОННЫХ УЧЕБНИКОВ

Итак, перейдем к характеристике электронных учебников.

1. Заслуга электронного учебника состоит прежде всего в том, что в нем реализуется принцип наглядности в обучении. Мы все знаем, что необходимость принципа наглядности в обучении была обоснована еще в XVII в. выдающимся чешским педагогом Яном Амосом Коменским, который создал классно-урочную систему, в условиях которой мы находимся по сей день. И он еще написал мало кому известную книгу учебник «Мир чувственных вещей в картинках», в которой уже на первой странице мы видим нарисованного в полный рост человека с соответствующими надписями: «это человек», «это голова», «это лоб», «это глаза», «это ухо» и т. А.

Принцип наглядности в учебном процессе, насколько это было возможно, реализовывался всегда. Но существовал вопрос: в какой степени эту наглядность можно было представить в обычной книге-учебнике? В какой степени, например, школьнику на одном из уроков химии будет понятен процесс получения кислорода в лаборатории? Или, в дополнение к теоретическому материалу, ученик в ту же секунду может увидеть видеоролик на эту тему?

2. В очень обобщенном схематическом виде образовательный процесс в школе можно представить в виде трех основных составляющих: собственно личность учащегося, содержание образования, адресованное этой личности, и методы обучения, с помощью которых данное содержание и будет транслироваться ученику. За многовековую историю развития образования учеными и практиками написаны сотни тысяч книг, монографий, учебников, научных статей, посвященных решению той или иной проблемы. Возникает вопрос: почему, несмотря на такие достижения, не происходит существенных изменений в реальной жизни? Вновь ставятся уже известные проблемы, и снова пытаются найти их решения. А дело в том, что если исследователь пытается, например, решить проблему развития интеллектуальных способностей ученика, то он не рассматривает, как правило, вопрос, а на каком содержании интеллектуальные способности будут развиваться. Аругой исследователь написал пособие по патриотическому воспитанию школьников, но не ставил задачу разработки принципиально новых методов патриотического воспитания и использует традиционно существующие. Поэтому ожидаемого результата не получается, и проблемы так и остаются не решенными.

Использование электронных учебников, на мой взгляд, позволяет в какой-то степени снять обозначенное противоречие, существующее в системе «ученик - содержание - методы». Появляется новая парадигма взаимодействия, когда ученик сам руководит своей образовательной, познавательной деятельностью; содержание образования, представленное в том числе наглядно и трудное для понимания, становится более доступным, а используемые методы (современные электронные средства, технологии) являются привлекательными.

Подобный материал ученику трудно представить в своем воображении. Точно так же и в высшей математике существуют разделы, которые нельзя увидеть в реальном мире (n-мерные пространства, поля и т. д.). Но, увидев такие модели, ученик может заинтересоваться и сложными для понимания темами. Феноменология содержания школьного образования заключается в том, что, изучая, казалось бы, устаревший для современной жизни материал, выпускник успешно продолжает дальнейшее обучение в университете и может делать открытия в современной науке.

Более того, все эти вещи позволяют в реальной школьной практике в процессе обучения использовать такие редкие методы обучения, как импрессивные и экспрессивные. 
Имрессивные методы обучения сводятся к организации участия учащихся в соответственно экспонированных ценностях, в том числе и научных. Экспрессивные методы основаны на создании ситуаций, в которых участники сами создают или воссоздают конкретные ценности, как бы выражая себя и одновременно переживая их.

3. В процессе обучения всегда стояла проблема формирования познавательного интереса школьника, проблема мотивации учения. Еще совсем недавно учителя при составлении плана урока должны были формулировать воспитательную цель урока. Это было обязательное требование. Затем о воспитании в школе на некоторое время забыли, сегодня вновь к нему возвращаемся. Я являюсь сторонником педагогической теории известного немецкого педагога Гербарта Петсалоцци, который сформулировал принцип «воспитывающего обучения». Мне представляется, что воспитание как самоцель не очень эффективно. Но личность учителя может быть уникальным примером, образцом для ученика как на уроке, так и в жизни. Причем, как правило, учитель такой задачи перед собой и не ставит. И ученик на сознательном уровне такой задачи не ставит, но тем не менее в какой-то момент мы можем увидеть вот такой результат. $\mathrm{O}_{\mathrm{A}}$ нажды на выпускном вечере один студент-выпускник подходит ко мне и говорит: «Вячеслав Алексеевич, я за вами наблюдаю пять лет, вы всегда носите белую рубашку, но ведь ее нужно стирать каждый день!» Подобные вещи нам и в голову не приходят. Но, оказывается, за нами наблюдают, с нас порой берут пример и делают выводы.

Следует также сказать, что не нужно ждать благодарности от наших подопечных (учащихся, студентов) сиюминутно, особенно не следует обижаться и реагировать, как нам кажется, на несправедливое к нам отношение. Приведу пример. Однажды одна взрослая студентка-выпускница вечернего отделения, которая хорошо училась, подошла ко мне и сказала: «Я окончила институт». Я ей ответил: «Ну я вас поздравляю!» Вдруг она мне: «Но не благодаря вашей математике» (я в тот период преподавал математику). На что я ответил: «Ну вам видней, благодаря чему», отвернулся и пошел. Вдруг она меня догоняет и говорит: «Ну и благодаря математике, конечно, тоже!» Этот пример говорит о том, что мы не должны реагировать на сиюминутное поведение учащихся, студентов, а должны им давать время, пусть и в далеком будущем, вновь возвратиться и переосмыслить свои поступки.

В процессе изучения «Основ православной культуры» я обратил внимание на картинку, подготовленную для выполнения теста под названием «Священные тексты». Казалось бы, речь идет о православной культуре, но как важно в условиях многонациональной страны, в условиях многонационального состава учащихся в классе показать учащимся основные священные книги: Библию, Коран, Тору, Трипитаку, представляющие религии - христианство, ислам, иудаизм, индуизм. Маловероятно, что в реальной жизни все эти книги учащиеся так легко могут найти и увидеть. Все это способствует воспитанию толерантности, терпимости, уважительного отношения к другой вере. Хотя я не сторонник термина «толерантность». Нашему менталитету ближе понятие «ненасильственное действие», или «ненасильственное взаимодействие», механизм которого нами разработан и успешно реализуется во многих учебных заведениях (Маралов, Ситаров, 2012).

И еще. Аети хотят воспитываться вместе со своим учителем независимо от национальности, религии, места проживания. Приведу такой пример из своей педагогической практики. Получив специальность «математика на французском языке», я работал преподавателем в одной из стран Центральной Африки - Конго (Браззавиль), в далекой глубинке, лишенной каких-либо признаков цивилизации. Классы были мно- 
гочисленные - более 70 учеников в каждом классе. Но каждый раз, несмотря на безупречную дисциплину, они находили какой-либо повод, требующий их наказания. Цель была одна - я их наказываю, а они после уроков с ножами мачете приходят к школе косить высокую траву, включают музыку, танцуют, и на их лицах радость от того, что мы все вместе проводим время.

4. Как мы знаем, в педагогической науке и педагогической практике всегда существовала и существует проблема поиска каких-то новых подходов, технологий, приемов обучения и т. А. Аля получения соответствующего результата. Если проследить историю образования в нашей стране, то окажется, что имелось большое количество различных реформ, нововведений, но все они были очень короткими. Они быстро начинались и быстро заканчивались. Это как у дошкольника: появилась новая игрушка, но быстро надоела. Например, в 1970-е годы было модным «проблемное обучение», одними из основателей которого были известные ученые педагоги-психологи М. И. Махмутов, А. М. Матюшкин. Проблемное обучение основывается на аналитико-синтетической деятельности обучающихся, реализуемой в размышлении, рассуждении. На самом деле это очень интересная и перспективная технология обучения. Она имеет огромный научный и практический потенциал, который еще до сих пор не раскрыт. Почему? Потому что для его использования требуется серьезная подготовка учителя вместе со своими учащимися. Аля удобства его использования М. И. Махмутов четко разграничил все употребляемые в проблемном обучении термины и дал их определения, а их достаточно много: вопрос, задача, проблема, проблемная ситуация, проблематизация, проблемное обучение и др. (Ситаров, 2009).

О сложности использования проблемного обучения в школьной и вузовской практике говорит и тот факт, что за последние десятилетия защитилось всего несколько докторских и кандидатских диссертаций, связанных в той или иной степени с данной технологией обучения. Например, Е. В. Ковалевская предложила алгоритм создания ступенчатой проблемной ситуации при изучении иностранного языка в вузе: «Вам нужно быть в институте, но...»: 1. Вы не можете уйти, потому что ждете важный телефонный звонок...; 2. Вы просите соседа отвезти вас в институт, но он отказывается, потому что...; 3. Вы едете автобусом, но не успеваете взять билет, входит контролер...; 4. Автобус уходит, вы останавливаете такси, но появляется человек, который опаздывает на самолет...; 5. Вы останавливаете машину, но по дороге водитель нарушает правила дорожного движения...; 6. Вы приезжаете в институт, но у вас нет кошелька (денег), чтобы оплатить проезд...; 7. Вам удается оплатить проезд, но вы опоздали на лекцию... (Ковалевская, 2000аb).

В электронных учебниках, подготовленных издательством «Арофа», представлены достаточно интересные видеоматериалы, создающие проблемную ситуацию, которая является исходной позицией, ключевым моментом в реализации проблемного обучения. Например, при изучении темы «Постоянные магниты. Магнитное поле постоянных магнитов» учащимся предлагается такое задание: «Аугообразный магнит поднесите к листу картона. Магнит не притянет его. Затем положите картон на мелкие гвозди и снова поднесите магнит. Аист картона поднимется, а за ним и гвозди. Объясните явление». Аругой пример. При изучении темы «Электризация тел при соприкосновении. Взаимодействие заряженных тел» предлагается такая проблемная ситуация: «Наэлектризуем один воздушный шарик о газету, а другой о кусок шерстяной материи. Подвесим их на некотором расстоянии друг от друга. Почему они притягиваются? Объясните наблюдаемое явление». 
5. Всегда существовала и существует проблема преемственности между разными ступенями, уровнями образования, в том числе между школой и вузом.

Исходя из своего личного опыта, могу сказать, что между сельской средней школой, которую я оканчивал, и математическим факультетом МГПИ имени В. И. Аенина, на который я поступил учиться, была просто пропасть. Этот фактор учитывался даже при зачислении на первый курс. Обычно на первый курс нашего факультета принимали процентов на 40 больше, чем требовалось, с учетом будущих отчислений, и особенно первокурсников. Но мы старались учиться, старались преодолеть все трудности самостоятельно, у нас не было электронных учебников, не было и такого количества различных методических пособий. Многие гордились тем, что ежедневно входят в здание, на табличке которого было слово «университет» или «институт». Однажды одна иногородняя женщина, жена военнослужащего, мне - первокурснику - поведала некую свою тайну: «Ты знаешь, каждый раз, когда я приезжаю в Москву, я специально доезжаю до высотного здания МГУ и поднимаюсь по его ступенькам, которые я даже готова целовать. Ты не представляешь, как я завидую студентам, которые по ним поднимаются каждый день и учатся в этом здании!» К сожалению, прошли те времена особого отношения к высшему образованию как к ценности.

Но проблема преемственности существует и сегодня, например, связанная с содержанием изучаемого материала. Есть вузовские дисциплины, в которых ряд тем имеет непосредственную связь с изучаемыми в школе.

Как известно, существуют различные формы восприятия информации и научного знания и различные способы их получения. Наиболее распространенными являются визуальные, аудиальные и кинестетические. Визуальный способ получения информации основан преимущественно на зрительном образе. Считается, что большинство людей воспринимает мир визуально. Хотя, конечно, мы воспринимаем мир, используя все репрезентативные системы, и электронные учебники предоставляют такую возможность, особенно когда это касается таких сложных и спорных дисциплин, как история. Мы знаем, какие острые дискуссии ведутся в последние годы вокруг содержания, например, истории России.

Возьмем в качестве примера электронный учебник «История России. 10 класс». Тема «Великая Отечественная война. Начало Великой отечественной войны». Подобная тема изучается и студентами первого курса в учебной дисциплине «История России». С одной стороны, всем известно начало Великой Отечественной войны, с другой обычный учебник не предоставляет такой широкой возможности, как электронный учебник, увидеть большое количество конкретных фотографий, иллюстрирующих такую трагедию. В обычном учебнике сделать подобное технически невозможно.

Наглядно-образное мышление, конечно, способствует адекватному восприятию, пониманию изучаемого материала. Каждое новое поколение все более удаляется от этих событий, и очень важно сформировать у учащихся мировоззрение на основе увиденного, услышанного, прочитанного. Аудиальный способ получения информации опирается в основном на слуховой канал информации.

Конечно, очень хорошо, что в электронном учебнике при изучении этой темы ученикам предоставлена возможность посмотреть фрагмент фильма «Парень из нашего города», который, естественно, побуждает «зрителей» к дальнейшему обсуждению увиденного. Наглядно-образное мышление позволяет человеку многогранно и разнообразно отражать объективную действительность. Этому, конечно, способствуют художественные фильмы, содержание песен и т. А. 
Обсуждение увиденного, услышанного, прочитанного нужно обязательно делать, поскольку очень часто мы, преподаватели, заблуждаемся, и нам кажется, что как воспринимаем окружающий мир мы, так же его воспринимают (или должны воспринимать) и все остальные. Но это далеко не так. Например, после просмотра небольшого фрагмента фильма Ким Ки Аука «Весна. Аето. Осень. Зима. И снова весна» в процессе изучения курса «Педагогика и психология ненасилия в образовании» студенты пишут эссе, посвященное проблеме взаимодействия между учителем и учеником. И каждый раз находится достаточно большая группа студентов, которая обращает внимание на такие детали, которые являются для них существенными, самыми важными, ключевыми, но остаются не замеченными другими. Поэтому следует всегда проводить дискуссии об увиденном, услышанном, прочитанном и, конечно, поддерживать творческих, нестандартно думающих учащихся.

6. Всегда существовала проблема межпредметных связей. Иногда эта проблема искусственно создавалась, иногда действительно была в реальной школьной практике. Если посмотреть электронный учебник по географии, то можно увидеть, каким образом различные школьные предметы - география, физика, химия, история - взаимопереплетаются.

7. Очень обидно, что сейчас многие выпускники школ, ориентируясь на гуманитарное образование, предпочтение отдают ему только потому, что испытывали очень большие трудности при изучении школьного курса математики. Хотя кажется это странным. На самом деле математика мне кажется очень легким предметом, поскольку одно вытекает из другого. Но, видимо, на каком-то этапе изучения математики ученик еще в начальной школе сталкивается с препятствием, какой-то материал ему непонятен, и он или боится, или стесняется сказать учителю, родителям и т. А. А дальше все накапливается быстро как снежный ком, и уже бывает очень трудно, а порой и невозможно наверстать упущенное. Использование электронного учебника, в котором есть объяснение учителем нового материала, последовательность построения геометрической фигуры и т. А., помогает ученику в процессе самостоятельной работы. Благодаря учебнику школьник может преодолеть этот барьер и посмотреть, и прослушать объяснение этого материала столько раз, сколько ему необходимо для понимания.

\section{ЗАКАЮЧЕНИЕ}

И в заключение следует отметить, что мы стоим в самом начале использования электронных учебников в школе. Они также уже давно используются и в вузе, но там это пока носит добровольный характер. Не все студенты, однако, положительно относятся к различным мультимедийным средствам. Некоторые говорят, что это их отвлекает, и они предпочитают записывать новый материал под диктовку. Конечно, все эти индивидуальные особенности и учеников, и студентов мы должны учитывать.

Но когда мы говорим о формировании субъектности личности учащегося или студента, то, конечно, использование электронного учебника, безусловно, этому способствует. Он - учащийся - сам управляет своей учебно-познавательной деятельностью. Благодаря видоизменению технологий в системе взаимодействия учитель ученик, ученик - ученик и т. А. (появляются новые формы взаимодействие - в чатах, через скайпы, электронную почту и т. д.) происходит развитие коммуникативных способностей.

Насколько мне известно, уже давно обоснован принцип мультимедийности (СтароАубцев, 2004), который формулируется как целенаправленное и целесообразное при- 
менение методологии искусства в развертывании содержания образования. Речь идет о взаимной дополнительности методов познания науки и искусства в образовании.

Но, завершая свое выступление, хочу напомнить о том, что существует педагогическое мастерство, в которое включается прежде всего мастерство учителя преподносить новый материал, вовлекая учащихся в этот познавательный процесс. Аавно известно, что вовлеченность учителя в учебный процесс есть условие вовлеченности ученика. Педагогическое мастерство учителя можно сравнить с мастерством актера все произносят одни и те же слова, но одному актеру зал рукоплещет и вызывает на бис, а у другого актера зрители покидают зал. То же самое и в школе, и в вузе: не у каждого учителя (преподавателя) получается так, как хотелось бы.

Ааже самый плохой учитель хочет, чтобы у него были хорошие результаты. Но у него не получается. Есть надежда, что появление электронных учебников и школе, и в вузе изменит подобную ситуацию к лучшему. Образ учителя накладывает свой отпечаток на ученика, который может сохраняться всю жизнь. Ученик, выбравший профессию учителя, уже на школьной скамье знает, как он будет объяснять новый материал, как он будет спрашивать, наказывать, работать с родителями и т. А. Откуда это взялось у него? Конечно, навеяно образом или конкретного учителя, или образом нескольких любимых и уважаемых учителей. Еще будучи дошкольником, я знал свою будущую учительницу сельской малокомплектной школы, где один учитель на два класса. Каждый раз, если я видел ее проходящей по деревне мимо нашего дома, я ей рассказывал новое выученное стихотворение. Она вырывала из школьной тетради чистый листок и на нем рисовала огромную пятерку. Я еле дождался, когда пойду в первый класс. И первого сентября сказал всем, что буду учителем.

Поэтому я хочу всем вам пожелать, чтобы и в памяти ваших учеников на всю жизнь остался такой же теплый след.

Всего вам доброго и спасибо за внимание!

\section{СПИСОК АИТЕРАТУРЫ}

Ковалевская, Е. В. (2000а) Проблемное обучение. Подход, метод, тип, система (на материале обучения иностранным языкам) : в 2 кн. М. : МНПИ. Кн. 1. 287 с.

Ковалевская, Е. В. (2000b) Проблемное обучение. Подход, метод, тип, система (на материале обучения иностранным языкам) : в 2 кн. М. : МНПИ. Кн. 2. 256 с.

Маралов, В. Г., Ситаров, В. А. (2012) Педагогика и психология ненасилия в образовании. М. : Юрайт. 424 с.

Ситаров, В. А. (2009) Проблемное обучение как одно из направлений современных технологий обучения // Знание. Понимание. Умение. № 1. С. 148-157.

Ситаров, В. А. (2014) Теория обучения. Теория и практика : учебник для бакалавров. М. : Юрайт. 447 с.

Стародубцев, В.А. (2004) Проектирование и реализация комплексов мультимедийных дидактических средств в педагогическом процессе вуза : автореф. дис. ... А-ра пед. наук. Барнаул. 43 с.

Аата поступления: 13.06.2015 г.

\section{ELECTRONIC TEXTBOOKS IN EDUCATIONAL SPACE \\ V. A. SITAROV \\ (MOSCOW UNIVERSITY FOR THE HUMANITIES)}

On June 12, 2015 Drofa Publishers (Moscow) held a webinar on "Electronic textbook form in educational space: Learn to study in a new way. Electronic textbooks by Drofa as a step towards higher 
education”. The invited keynote speaker was V. A. Sitarov, Doctor of Pedagogy, Professor and Chair at the Department of Pedagogy and Psychology of the Higher School, Moscow University for the Humanities.

The article text is a full transcript of the keynote, which concentrated on the important additions electronic education can make to complement its traditional forms. It was previously held that knowledge and information were not closely linked, and even contradicted each other. Schoolbooks set out "knowledge" as they have to match certain hierarchically organized demands or epistemical criteria. Since information does not possess such criteria, it is not included into school textbooks. At the same time, information is very attractive and offers many sources for school students and adults to obtain it from. The emergence of electronic textbooks favors the inclusion of additional information which expands and complements the schoolbook's normative content. It is supposed to encourage the student's interest in the subject and thus to remove the contradiction between knowledge and information.

The keynote outlines the main features of electronic textbooks. Their main achievement is implementing the principle of visuality, allowing thus to eliminate the opposition between the learner, educational content and methods of study. It provides an opportunity to solve the problems of study motivation, personality development, to shape the notions of interconnection between disciplines. At the same time, it is important to emphasize the need for personal contact between the educator and the student, as well as for teaching by the educator's example.

Keywords: webinar, electronic textbooks, informational learning environment, electronic education, means of electronic education.

\section{REFERENCES}

Kovalevskaia, E. V. (2000a) Problemnoe obuchenie. Podkbod, metod, tip, sistema (na materiale obucheniia inostrannym iazykam) [Problem-based tuition: Approach, type, method, system (A case study of foreign languages teaching)] : in 2 books. Moscow, MNPI. Bk 1. 287 p. (In Russ.).

Kovalevskaia, E. V. (2000b) Problemnoe obuchenie. Podkbod, metod, tip, sistema (na materiale obucheniia inostrannym iazykam) [Problem-based tuition: Approach, type, method, system (A case study of foreign languages teaching)]: in 2 vols. Moscow, MNPI. Bk 2. 256 p. (In Russ.).

Maralov, V. G. and Sitarov, V. A. (2012) Pedagogika i psikbologiia nenasiliia vobrazovanii [Pedagogics and psychology of non-violence in education]. Moscow, Iurait Publ. 424 p. (In Russ.).

Sitarov, V. A. (2009) Problemnoe obuchenie kak odno iz napravlenii sovremennykh tekhnologii obucheniia [Education through problem solving as a trend in modern educational technologies]. Znanie. Ponimanie. Umenie, no. 1, pp. 148-157. (In Russ.).

Sitarov, V. A. (2014) Teoriia obucheniia. Teoriia i praktika [Theory of tuition. Theory and practice] : An undergraduate textbook. Moscow, Iurait Publ. 447 p. (In Russ.).

Starodubtsev, V. A. (2004) Proektirovanie i realizatsiia kompleksov mul'timediinykb didakticheskikb sredstv $v$ pedagogicheskom protsesse vuza [Building and implementing multimedia didactical systems into studying at an institution of higher education] : abstract of the diss. ... Doctor of Pedagogy. Barnaul. 43 p. (In Russ.).

Submission date: 13.06.2015.

Ситаров Вячеслав Алексеевич - доктор педагогических наук, профессор, заведующий кафедрой педагогики и психологии высшей школы Московского гуманитарного университета. Адрес: 111395, Россия, г. Москва, ул. Юности, д. 5. Тел.: +7 (495) 374-74-59. Эл. адрес: sitarov@mail.ru

Sitarov Viacheslav Alekseevich, Doctor of Pedagogy, Professor and Chair, Department of Pedagogy and Psychology of the Higher School, Moscow University for the Humanities. Postal address: 5 Yunosti St., 111395 Moscow, Russian Federation. Tel.: +7 (495) 374-74-59. E-mail: sitarov@mail.ru 